\title{
A case report of laparoscopic ipsilateral ureteroureterostomy in children with renal duplex
}

This article was published in the following Dove Press journal:

Research and Reports in Urology

26 February 2016

Number of times this article has been viewed

\section{Yuen Shan Wong \\ Yuk Him Tam \\ Kristine Kit Yi Pang \\ Division of Paediatric Surgery and Paediatric Urology, Department of Surgery, Prince of Wales Hospital, The Chinese University of Hong Kong, Shatin, NT, Hong Kong}

Correspondence:Yuk Him Tam Division of Paediatric Surgery and Paediatric Urology, Department of Surgery, Prince of Wales Hospital, The Chinese University of Hong Kong, Shatin, NT, Hong Kong

Tel +852 26322953

Email pyhtam@surgery.cuhk.edu.hk
Abstract: We report on two children aged 2 and 6 years, who underwent laparoscopic ipsilateral ureteroureterostomy for their renal duplex anomalies. Both patients had complete duplex and were investigated by ultrasound, micturating cystourethrogram, magnetic resonance urography, and radioisotope scan. One patient had high-grade vesicoureteral reflux to lower moiety complicated with recurrent urinary tract infections, while the other had obstruction to upper moiety due to ectopic ureter. The pathological moieties of both patients were functional. Both patients underwent laparoscopic ipsilateral ureteroureterostomy uneventfully without any intraoperative complications. Postoperative imagings confirmed successful outcomes after surgery.

Keywords: laparoscopic ipsilateral ureteroureterostomy, renal duplex, children

\section{Introduction}

Renal duplex can be complete or partial. Complete duplex features a complete pyeloureteral duplication with the two ureters entering the bladder separately. Complete renal duplex does not necessarily result in pathological conditions, which, if present, are usually associated with ureteroceles, ectopic ureters, vesicoureteral reflux (VUR), or their combinations. Ureteroceles and ectopic ureters are always associated with upper moiety (UM), while VUR more commonly affects the lower moiety (LM). ${ }^{1}$

Indications for surgery in renal duplex include continuous urinary incontinence due to ectopic ureter, obstruction associated with ectopic ureter or ureterocele, and recurrent urinary tract infection (UTI) associated with VUR. Hemi-nephrectomy with partial or complete ureterectomy is commonly performed when the pathological moiety is non- or poorly functioning, and approaches by minimally invasive surgery (MIS) have been shown to be a safe alternative to open surgery. ${ }^{2-4}$ In the context of an affected moiety being functional, however, ipsilateral ureteroureterostomy (IUU) is a well-established option to preserve the pathological moiety provided the other moiety is normal without any obstruction or VUR.$^{5-7}$ We hereby report on two cases of IUU performed laparoscopically in children with renal duplex associated with pathological but functional moieties.

\section{Case I}

A 6-year-old girl presented with repeated UTIs. Ultrasound and magnetic resonance urography confirmed left complete renal duplex with hydroureteronephrosis in LM. There was no dilatation at UM. Micturating cystourethrogram (MCUG) confirmed grade IV VUR to LM. The VUR failed to resolve after cystoscopic Deflux injection 
and UTIs recurred. Dimercaptosuccinic acid (DMSA) scan confirmed functioning left LM. She underwent laparoscopic IUU with the UM ureter being the recipient ureter and the dilated LM ureter being the donor ureter. The operating time was 315 minutes without any intraoperative complications. Normal diet was resumed on postoperative day 3 but the patient had fever. The preoperative urine culture result was subsequently available and showed the growth of extendedspectrum beta-lactamase Escherichia coli that was resistant to the perioperative cephalosporin group of antibiotics we had prescribed. The patient stayed in the hospital for 9 days after surgery and the prolonged hospital stay was required only to complete an intravenous course of antibiotics to which the urine culture was sensitive. The patient required a total of four doses of paracetamol and five doses of ibuprofen for postoperative fever and pain control. Ultrasound performed after removal of double-J catheter showed normal UM and resolution of LM hydronephrosis. The patient has remained UTI-free after 14 months of follow-up.

\section{Case 2}

A 2-year-old girl presented with antenatal diagnosis of right hydronephrosis and UTI. Postnatal ultrasound and magnetic resonance urography confirmed right complete renal duplex with severe UM hydroureteronephrosis without ureterocele and suggested ectopic UM ureter insertion below bladder neck. No dilatation was seen at LM. MCUG showed no VUR. DMSA and mercaptoacetyltriglycine (MAG3) scans showed functioning right $\mathrm{UM}$ with obstructed drainage. The patient underwent laparoscopic IUU with LM ureter being the recipient ureter and the dilated UM ureter being the donor ureter. The operating time was 205 minutes without any intraoperative complications. The patient recovered uneventfully and was discharged on postoperative day 3 . The patient received only one dose of paracetamol for postoperative pain control. Ultrasound after removal of double-J catheter showed significant reduction of the right UM hydroureteronephrosis and normal LM. Postoperative MAG3 scan showed improved drainage of right UM with stable differential renal function. Parental consent was obtained for the release of related medical information for this study. Formal ethics approval has been sought and is expected to be obtained for this study from the Institutional Review Board of Prince of Wales Hospital, The Chinese University of Hong Kong, as this is a retrospective review.

\section{Surgical techniques}

In both patients, the procedure started with cystoscopy to cannulate the recipient ureter. In Case 1, we cannulated the left UM ureter with a 3 Fr ureteral catheter and during the laparoscopic procedure, we used a combined cystoscopic and laparoscopic approach to change to a double-J catheter which bridged the anastomosis with its proximal end at the pathological LM renal pelvis. In Case 2, we used a different approach in which the recipient right LM ureter was stented with double-J catheter at the beginning and the catheter was left in place in the recipient ureter without going across the anastomosis at the end of the laparoscopic procedure.

We inserted a $5 \mathrm{~mm}$ umbilical port for the telescope by open method and two other working ports, 3 and $5 \mathrm{~mm}$, at the ipsilateral flank just below the umbilical level and the hypogastrium. The use of a $5 \mathrm{~mm}$ working port facilitated the delivery of suture needles into the peritoneal cavity and only $3 \mathrm{~mm}$ laparoscopic instruments were used for the whole procedure. The pelvic peritoneum was incised below the bifurcation of common iliac vessels to identify the two ureters. The recipient ureter could be easily identified by the presence of the stent (Figure 1) and the dilated donor ureter was dissected free from the recipient ureter distally as close to the bladder as possible while safeguarding the periureteral adventitia with its blood supply. The donor ureter was divided and the distal stump was excised after ligation using endoloop.

From the lessons learned in Case 1, we found that stabilizing the recipient ureter was crucial for creating the longitudinal ureterotomy and the anastomosis. Therefore, in Case 2, we placed two transabdominal holding sutures using a 4-zero polydioxanone straight needle, going through the recipient ureter without hitching its wall or compromising its adventitial blood supply (Figure 2). We placed only one holding suture in

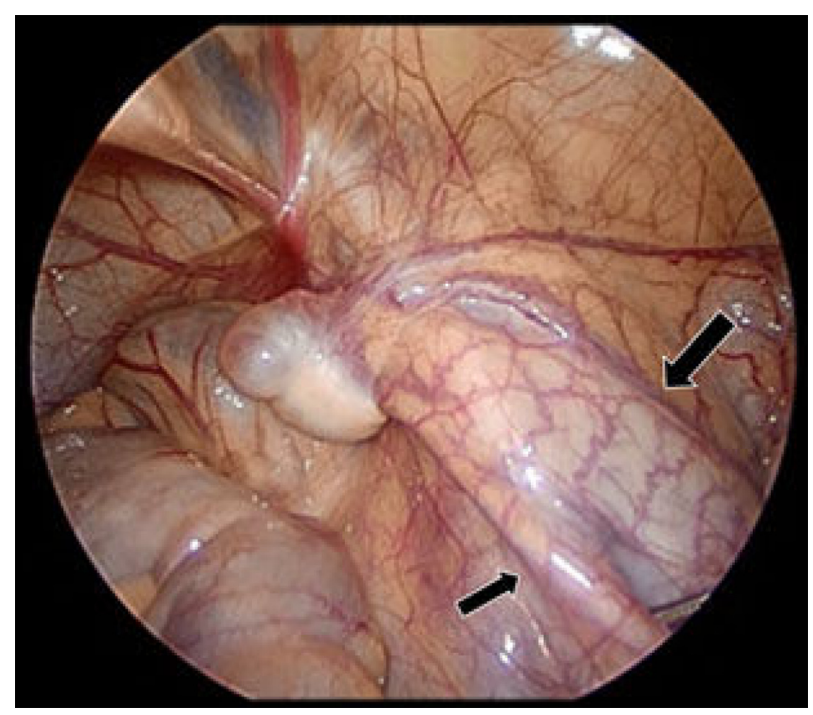

Figure I The recipient ureter easily identified by the presence of the stent. Notes: Thin arrow points at recipient ureter; thick arrow points at dilated donor ureter. 


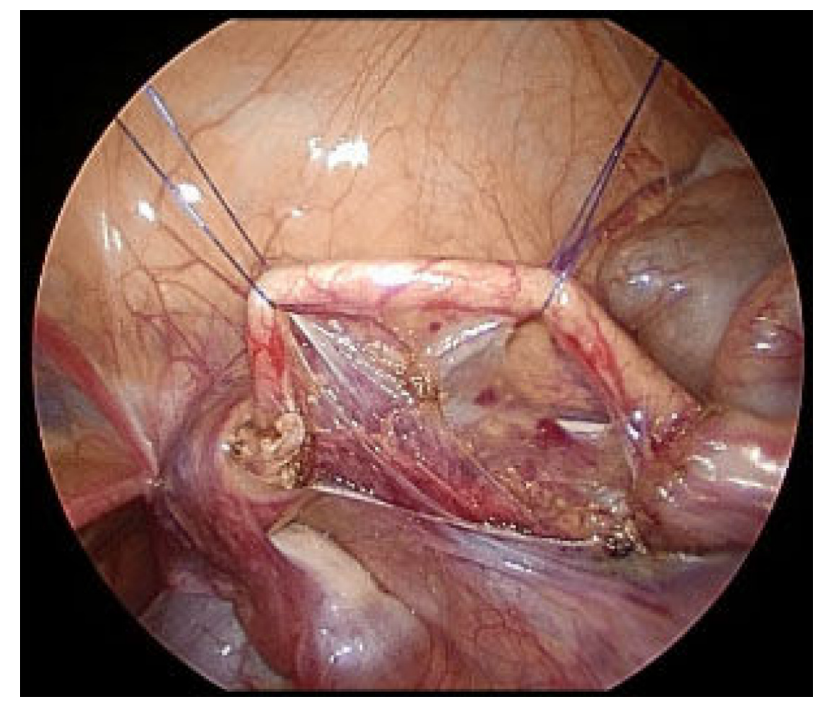

Figure 2 Lifting a segment of recipient ureter by two transabdominal holding sutures.

Case 1. A longitudinal ureterotomy was made by scissors on the anteromedial aspect of the recipient ureter that matched the size of the divided donor ureter (Figure 3). An end-to-side anastomosis was fashioned from proximal to distal end using 5-zero monofilament absorbable continuous running suture starting on the posterior side (Figure 4). A Foley catheter was left in place for free drainage of bladder after surgery. The double-J catheters were removed by cystoscopy at 9 and 5 weeks in Cases 1 and 2, respectively. The double-J catheter was kept longer in Case 1 as it was our first experience.

\section{Discussion}

IUU is an established reconstructive procedure in renal duplex when only one of the two moieties is pathological

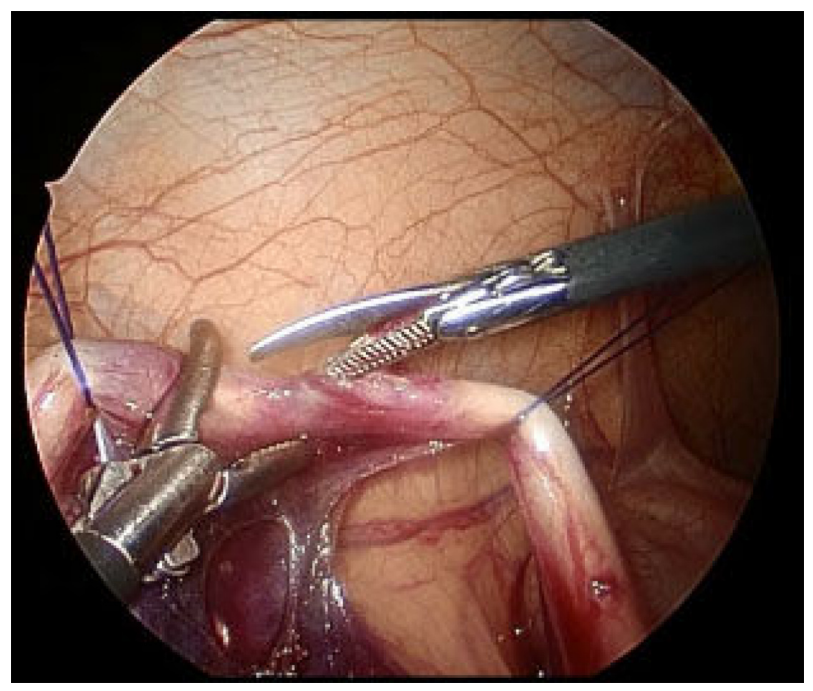

Figure 3 Longitudinal ureterotomy on recipient ureter.

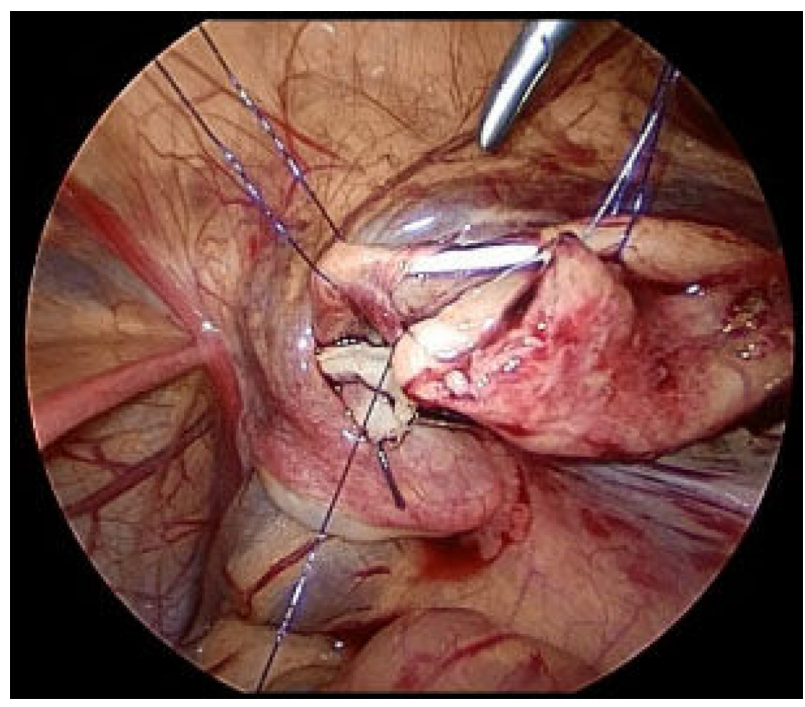

Figure 4 End-to-side ureteral anastomosis half completed on posterior side.

but the abnormal moiety remains functional. More recently, some investigators have suggested IUU as the primary procedure regardless of the function of the abnormal moiety with the advantage of lower risks than hemi-nephrectomy. ${ }^{8}$ We perform IUU selectively in those pathological moieties that still have significant function, and in the more common situations where the abnormal moiety is poorly functioning, hemi-nephrectomy is performed following the traditional principles. ${ }^{9}$

We have previously reported our experience of heminephrectomy in children with renal duplex by conventional laparoscopy and single-site laparoscopy with low complication rates. ${ }^{10}$ Significant loss of renal function of the remaining moiety has been reported in $8 \%$ of the patients after open hemi-nephrectomy. ${ }^{11}$ Hemi-nephrectomy by MIS has the possible advantage over open surgery of inducing less vasospasm or vascular injury to the remaining moiety, ${ }^{9}$ and is our preferred treatment in renal duplex except when the pathological moiety is still functional as in these two cases.

Literature data regarding laparoscopic IUU remain very limited. Small case series reported in recent years have found that laparoscopic IUU is a safe and effective alternative to open surgery with the potential advantages of better cosmesis and less postoperative pain. ${ }^{12-14}$ In our institution, we have performed laparoscopic pyeloplasty routinely, for pelvi-ureteric junction obstruction in children, for more than a decade. ${ }^{15}$ The acquisition of the laparoscopic skills in performing anastomosis in ureters has prepared us for the less common reconstructive procedure of laparoscopic IUU.

We opted for the low approach in performing laparoscopic IUU instead of the proximal approach preferred by some 
investigators. Storm et al explained their preference for laparoscopic proximal IUU due to its similarities to laparoscopic pyeloplasty in port placement and surgical techniques despite the need to mobilize the colon or creation of transmesenteric window, which will not be required if a low approach is used. ${ }^{14}$ In early studies of open surgery, concern was raised for the potential effect of "yo-yo" reflux associated with a distal IUU, ${ }^{16}$ but clinically significant effect was not substantiated in subsequent studies. ${ }^{17,18}$ In addition to the relative ease to mobilize the two ureters after incising the pelvic peritoneum in the low approach, we believe another advantage is to allow adequate resection of the distal stump of the dilated donor ureter. Reoperation for recurrent infection of the retained ureteral stump has been reported in $12.2 \%$ of patients after proximal IUU. ${ }^{19}$ The low approach working toward the pelvis suits most the laparoscopic resection of the abnormal dilated ureter distally close to bladder.

It is important not to create spiral incision into the recipient ureter when making the longitudinal ureterotomy. We found both the ureteral stent in the recipient ureter and the two holding sutures very important during this difficult step. Using a grasper alone to hold onto the recipient ureter induces too much trauma onto the precarious adventitial blood supply while not keeping the recipient ureter steady enough. After the lessons learned from Case 1, we placed two transabdominal sutures instead of one to lift a segment of the recipient ureter which we intended to make the ureterotomy in Case 2. The ureteral stent in the recipient ureter provided support during the ureterotomy and prevented accidental cutting onto the back wall.

It may be a matter of debate whether the double-J catheter should bridge the anastomosis with its proximal end in the donor pelvis or should just be left in the recipient ureter. We performed the procedure differently in our two patients. In Case 1, after we had completed the posterior side of the ureteral anastomosis, we passed in a guidewire through the ureteric catheter, laparoscopically retrieved the guidewire at the half-completed anastomosis, and placed the guidewire across the anastomosis up to the donor pelvis. The double-J catheter was then inserted over the guidewire under combined laparoscopic, cystoscopic, and fluoroscopic guidance.

After reviewing the experience in the first patient, we found that the most crucial point during the ureteral anastomosis is to prevent obstruction at the apex of the anastomosis on the recipient ureter as the recipient ureter is nondilated and more vulnerable to narrowing. Any obstruction on the recipient side of the anastomosis subjects an initially normal moiety to poten- tial damage. By bridging the anastomosis with the double-J catheter halfway through the anastomosis, the recipient ureter in our first patient was no longer stented at its proximal apex of the anastomosis, and we exercised extra caution to prevent suturing onto the back wall of the recipient ureter when we started the anterior wall of anastomosis. In the second patient, we modified our technique by leaving a double-J catheter in the recipient ureter before we started the laparoscopic procedure. The whole anastomosis was fashioned with the nondilated recipient ureter stented by the double-J catheter. In future, we will follow this practice and we believe leaving the double$\mathrm{J}$ catheter in the recipient ureter is convenient and may be more effective in protecting against obstruction on the side of recipient ureter. The shorter operating time in Case 2 may be attributed to both leaving the double-J catheter in the recipient ureter without traversing the anastomosis and placing two transabdominal holding sutures.

The suturing in laparoscopic IUU is meticulous but similar in complexity to that of laparoscopic pyeloplasty. Surgeons experienced in laparoscopic pyeloplasty should be competent to handle the ureteral anastomosis in laparoscopic IUU. With the increasing availability of robotic surgical platform, robot-assisted IUU has recently been reported. ${ }^{20}$ The technical advantages of the robotic system in reconstructive procedures make IUU another good indication for robotassisted urologic procedure in children.

\section{Conclusion}

This report demonstrates that laparoscopic IUU is a safe and effective alternative to open surgery in children with the advantages of short hospital stay and low postoperative analgesic requirement. The procedure requires that the surgeons be acquainted with the necessary skills for laparoscopic suturing in ureters which can be best acquired from laparoscopic pyeloplasty.

\section{Disclosure}

The authors report no conflicts of interest in this work.

\section{References}

1. Rickwood AM, Madden NP, Boddy SM. Duplication anomalies, ureteroceles and ectopic ureters. In: Thomas DF, Duffy PG, Rickwood AM, editors. Essential of Paediatric Urology, Second Edition. London: Informa Healthcare; 2008:93-108.

2. Denes FT, Danilovic A, Srougi M. Outcome of laparoscopic upper-pole nephrectomy in children with duplex systems. J Endourol. 2007;21: 162-168.

3. Garcia-Aparicio L, Kruael L, Tarrado X, et al. Hemi-nephroureterectomy for duplex kidney: laparoscopy versus open surgery. J Pediatr Urol. 2010;6:157-160. 
4. Mason MD, Anthony Herndon CD, Smith-Harrison LI, et al. Roboticassisted partial nephrectomy in duplicated collecting systems in the pediatric population: techniques and outcomes. J Pediatr Urol. 2014;10:374-379.

5. Choi H, Oh SJ. The management of children with complete ureteric duplication: selective use of uretero-ureterostomy as a primary and salvage procedure. BJU Int. 2000;86:508-512.

6. Lashley DB, McAleer IM, Kaplan GW. Ipsilateral uretero-ureterostomy for the treatment of vesicoureteral reflux or obstruction associated with complete ureteral duplication. J Urol. 2001;165:552-554.

7. Duthoy EJ, Soucheray JA, McGroarty BJ. Ipsilateral ureteroureterostomy for vesicoureteral reflux in duplicated ureters. $J$ Urol. 1977;118:826-828.

8. McLeod DJ, Alpert SA, Ural AZ, et al. Ureteroureterostomy irrespective of ureteral size or upper pole function: a single center experience. J Pediatr Urol. 2014;10:616-619.

9. Timberlake MD, Corbett ST. Minimally invasive techniques for management of the ureterocele and ectopic ureter upper tract versus lower tract approach. Urol Clin N Am. 2015;42:61-76.

10. Tam YH, Pang KK, Tsui SY, et al. Laparoendoscopic single-site nephrectomy and hemi-nephroureterectomy in children using standard laparoscopic setup versus conventional laparoscopy. Urology. 2013;82:430-435.

11. Gundeti MS, Ransley PG, Duffy PG, et al. Renal outcome following heminephrectomy for duplex kidney. J Urol. 2005;173:1743-1744.

12. Gonzalez R, Piaggio L. Initial experience with laparoscopic ipsilateral ureteroureterostomy in infants and children for duplication anomalies of the urinary tract. J Urol. 2007;177:2315-2318.
13. Steyaert HS, Lauron J, Merrot T, et al. Functional ectopic ureter in case of ureteric duplication in children: initial experience with laparoscopic low transperitoneal ureteroureterostomy. J Laparoendosc Adv Surg Tech A. 2009;19 (Suppl 1):S245-S247.

14. Storm DW, Modi A, Jayanthi VR. Laparoscopic ipsilateral ureteroureterostomy in the management of ureteral ectopia in infants and children. J Pediatr Urol. 2011;7:529-533.

15. Yeung CK, Tam YH, Sihoe JD, et al. Retroperitoneoscopic dismembered pyeloplasty for pelvi-ureteric junction obstruction in infants and children. BJU Int. 2001;87:509-513.

16. Belman AB, Filmer RB, King LR. Surgical management of duplication of the collecting system. J Urol. 1974;112:316-321.

17. O'Reilly PH, Shields RA, Testa HJ, et al. Ureteroureteric reflux. Pathological entity or physiological phenomenon? Br J Urol. 1984;56: 159-164.

18. Chacko JK, Koyle MA, Mingin GC, et al. Ipsilateral ureteroureterostomy in the surgical management of the severely dilated ureter in ureteral duplication. J Urol. 2007;178:1689-1692.

19. Lee YS, Hah YS, Kim MJ, et al. Factors associated with complications of the ureteral stump after proximal ureteroureterostomy. J Urol. 2012;188:1890-1894.

20. Leavitt DA, Rambachan A, Haberman K, et al. Robot-assisted laparoscopic ipsilateral ureteroureterostomy for ectopic ureters in children: description of technique. J Endourol. 2012;26:1279-1283.
Research and Reports in Urology

\section{Publish your work in this journal}

Research and Reports in Urology is an international, peer-reviewed, open access journal publishing original research, reports, editorials, reviews and commentaries on all aspects of adult and pediatric urology in the clinic and laboratory including the following topics: Pathology, pathophysiology of urological disease; Investigation and treatment of

\section{Dovepress}

urological disease; Pharmacology of drugs used for the treatment of urological disease. The manuscript management system is completely online and includes a very quick and fair peer-review system, which is all easy to use. Visit http://www.dovepress.com/testimonials.php to read real quotes from published authors. 